\title{
Subjective Well-Being of Adolescent Boys Living in Single-Mother Households in a Cape Town Suburb, South Africa
}

\author{
Olaniyi Bojuwoye PhD \\ Department of Educational Psychology, University of the Western Cape, Private Bag X 17 \\ Bellville 7535, Cape Town, South Africa \\ Email: obojuwoye@uwc.ac.za \\ Frederick Sylvester \\ University of the Western Cape, Department of Educational Psychology, Private Bag X 17 \\ Bellville 7535, Cape Town, South Africa
}

\section{Doi:10.5901/mjss.2014.v5n23p2017}

\section{Abstract}

The aim of the study was to explore experiences of a group of adolescent boys, living in single-mother households, regarding their satisfaction with various aspects of their family life. An interpretive/constructivist paradigm was adopted for describing and interpreting participants The study adopted interpretive/constructivist approach to investigate the subjective well-being of a group of adolescent boys in terms of their satisfaction with their family status, financial resources, social support and living environment of their single-mother family lives. Fifteen adolescent boys (aged 15 to 17 years)living in single-mother households were observed, interviewedindividually and on the collages they compiled and in groups. The study found the adolescent boys reported experiences to be characterized by negative emotionality and display of at-risk behaviour tendencies. The adolescent boys reported dissatisfaction with their family status, financial resources, social support and their family living environment to indicate their generally poor subjective well-beings. The study concludes that since financial insecurity of single-mother households is a major contributor to children's negative cognitive, emotional and behaviouraloutcomes, their optimaladjustment to life or well-being in single-mother households have to be provided for through public or government financed parental healthcare and support systems.

Keywords: adolescent boys, subjective well-being, single-mother households, family conditions, life satisfaction.

\section{Introduction}

Globally family status is tending towards single-parent family from the traditional nuclear family with two parents and their children (Popenoe, 1996, Vaaden-Kieman, Lalongo, Pearson, \& Kellam, 1995, Wright, 1994). In South Africa a third of families are single-parent households (Naran 2006). An estimated 40\% of the 18 million South African children are raised by single mothers (Prince, 2009). This changing family status is a worldwide phenomenon and not peculiar to South Africa. Over $40 \%$ of children in the United States of America, who yearly experience the divorce of their parents, live in single-parent households (Tanner, 2002). Studies in Australia (Pike, 2000) and Great Britain (Wiechers, 2003) found an estimated $40 \%$ of families, in each of these two countries, to be single-parent households.

In most single-parent households fathers are the absent parents (Sylvester, 2010).Mothers who are custodial parents earn less than their male counterparts, yet are forced to shoulder their family economic burdens leading to financial hardship,lowering of socio-economic status and lack of social support for those left in the family units (Acklin, 2008). Children whose fathers are absent from their households suffer economic and social deprivationsas well as deprivation from things they can learn from their fathers (Griesel-Roux, Ebersohn, Smit, \& Elloff, 2005). In almost all cases where the father's identity is relatively unknown or not known at all,children (particularly boys), suffer lack of father figure or same-sex role model (MacCallum, \& Golombok, 2004)..

Evidences of negative consequences of father absence on virtually every aspect of children's lives exist in the literature. For male children, particularly in patriarchal societies, absence of fathers often means the removal of parental authority from households (Pleck, 1997).For male children, absence of fathers from households also means absence of same-gender examples of appropriate behaviours, leading to display of negative emotions and problem behaviours (Daniels, \& Adams, 2009). Demuth and Brown (2004) found that boys growing up without a father figure show more 
antisocial behaviour tendencies than their counterparts living with their fathers and mothers. Passive anti-social behaviours, exposure to delinquent and at-risk behaviours have been found among boys whose fathers are absent from households (Sharma, \& Silbereisen, 2007). According to Chen (2007), absence of fathers from families is responsible for young adolescent boys' inability to learn a range of life skills and to grow in unique male ways and develop male interests, activities and social behaviours, within the context of their masculinity. Further consequences of absence of fathers from households for children include high incidences of anxiety, depression and at-risk behaviours leading to negative self-image or poor self-esteem, general dissatisfaction with life or poor subjective well-being (Laftman, 2010).

Manolis and Roberts (2011) describe subjective well-being simplyas happiness or overall cognitive and affective evaluations of one's life. Diener (2009) asserts that subjective well-being is how a person evaluates his or her life. A person's evaluation of life satisfaction is that person's reaction to what is happening in his or her life (Roberts, \& Clement, 2007). Proper evaluation of life satisfaction entails evaluating all the aspects or domains of life contributing to one's overall satisfaction with life.Domains of life contributing to one's subjective well-being include one's family and friends, feelings of self-worth, resilience, health, fun and enjoyment, money and job (Roberts, \& Clement, 2007). Subjective wellbeing, therefore, is the sum total or overall evaluation of the different components of life rather than an evaluation of a single domain (Diener, Suh, Lukas, \& Smith, 1999).

In terms of theory to explain evaluation of life satisfaction, Bronfenbrenner's (1979) ecological model states that, for children, life satisfactionis regulated at the micro or family level of social interactions. Hazan and Shaver (1994) argue that,since family members form basic everyday network, a child's cognitive or emotional reactions to what is happening in his or her life are regulated within the parameters of the protection, proximity and responsiveness of parents (Hazan, \& Shaver, 1994). Lahikainen, Tolonen and Kraav (2008) contend that family institution has a central responsibility for the overall well-being of children and that parents are the primary source and resource for children's subjective well-being. Parents bear responsibility for nurturing and protection of children from threats and insecurities in everyday life.A child's state of subjective well-being or life satisfaction is contingent upon the support received from the family including the amount of interest and attention by parents and siblings (Lahikainen et al. 2008).

The fundamental components or resources for regulating children's subjective well-being are essentially within the child-parent relationship domain. Hazan and Shaver (1994) and Lahikainen et al (2008) contend that components contributing to cognitive and emotional evaluation of life satisfaction in the family are best regarded as parental proximity, availability or responsiveness in terms of the amount of time parents are available to their children including the care and provision of nurturance, safety, security and other needs of the children. Fraley (2010), however, asserts that it is not only what happens within the family that contributes to children's subjective well-being but also what happens in the immediate environment outside of the family. Thus children's subjective well-being can be viewed as being produced, reproduced and maintained not only by seeking protection and proximity of parents but also by learning to know the immediate environment in which the family is located and learning to cope with the threats and solve problems emanating from the environment (Lahikainen et al. 2008). Subjective well-being,therefore, is socially interactive, communicative and contextual.

\section{The Study}

This study proceeded from the hypothesis that children's subjective well-being is a function of an array of indicators essentially regarding their family conditions. This study evaluated the participants' subjective well-beings by adopting Laftman's (2010) proposition which states that subjective well-being can be assessed from a child's reported experiences on a range of aspects of living conditions in the family. Lahikainen et all (2008) identified indicators of life satisfaction to include economic resources, social support, safety, security and other aspects within the family that can be linked to children's psychological and physical well-being (Lahikainen et al. 2008). Indicators of family living conditions to focus for children's subjective well-being, identified by Laftman (2010), include social support, health and economic resources.

This study investigated the subjective well-being of a group of adolescent boys who were asked to report on their experiences of living in single-mother households particularly in terms of their satisfaction with various conditions of their family life. The domains of family life the boys reported on include their satisfaction with their single-mother family status, family financial resources, social support (family interpersonal dynamics) and their satisfaction with the environment where their families lived. The inclusion of the family residential environment is informed by the researchers' belief that children's sense of well-being (satisfaction with life) is not only determined exclusively by what happens within the family, but also by what happens outside of the family or outside environment where the family live. Feelings of helplessness and insecurity are not only linked to conditions within the family but also to individual's relationship with the outer world outside of the family (Lahikainen et al. 2008). 
Implications of family type for children exists in the literature. However, not many of these works are based on reports from children themselves. Many of these previous works also focus mainly on implications of family type on children's academic achievement and not on other aspects of their lives (Denny, \& Martin, 2004; McLanahan, 2008). The broad meta-analysis study of single parenthood and child well-being, by Chapple (2009), has relevance only for OECD countries where the study was conducted. It has little relevance for countries in Africa. There is very scant literature onthe effects of family types on African children's subjective well-being especially as reported by the children themselves. The need for empirical data to inform policy decisions to address the implications of the growing trend of single-mother household phenomenon in a country like South Africa was, therefore, an important rationale for this study.

\subsection{Research Design}

An interpretive/constructivist paradigm was adopted for describing and interpreting participants' realities (internally and externally) as presented in their reported experiences (Merriam, 2002). Qualitative approach to the study enabled the researchers to focus on participants' meanings, interpretations and assessment of their life satisfaction with growing up in single-mother households. The reality of the social phenomenon of single-mother familyis best understood by exploring subjective meanings of individuals involved (Carr, \& Kemmis, 1986). Qualitative approach allowed for the description and interpretation of living in single-mother households in the context in which it was experienced and understood (Mash, \& Wolfe 2002). The approach also helped researchers to place the study participants at the centre of their actions, ideas, values and meanings, all of which constituted the critical information necessary for the study (Hitchcock, \& Hughes, 1999).

\subsection{Participants}

The adolescent boys in this study were drawn from a high school situated in asuburb community of Cape Town, South Africa, where single-mother households are prevalent. This community is characterized by low socio-economic conditions including poverty, unemployment, substandard housing, crime and violence.The fifteen adolescent boys who volunteered for the study were of mean age of 15 years and from grades 8, 9 and 10 of their community high school. Due to their age and educational levels the researchers considered them capable of expressing themselves very clearly and to describe their experiences satisfactorily. The selection of the participants was purposive since they had to fit into criteria of being adolescent and growing up in single-mother households. Purposive sampling is based on judgment as to presence of representative or conforming attributes of a population being studied (Bless, \& Smith, 1996). Since major effort in a qualitative research is to penetrate social life and be immersed in fruitful relationship with participants in order to address research topic in depth, qualitative study usually involves selection of a small number of cases (less than 20) in order to facilitate the researcher's close association with the participants (Crouch, \& McKenzie, 2006).

\subsection{Research Instruments}

The study collected comprehensive qualitative data including personal accounts of participants' experiences and satisfaction with various aspects of single-motherfamily life. The realities of growing up, without a father figure, are best reported by children involved in experiences which are likely to be fluid variable sets of social constructions, feelings, beliefs, attitudes and behaviours constituting essential information reflecting their satisfaction with various aspects of their single-mother family life (Terre-Blanche, \& Durrheim, 1999). Gathering such information, however, required employment of more than one method, hence the employment of semi-structured one-on-one individual interviews, focus group interviews, behaviour observations and compilations of collages.

Interviewis a good way of knowing and establishing rapport with people and getting to understand their feelings and experiences (Terre-Blanche, \& Durrheim, 1999). Interview provides opportunity for gathering descriptive data in subjects' own words, perspectives and interpretations of their worlds (Bodgan, \& Taylor 1999). The researchers interviewed the participants to obtain their unique ways of describing their worlds and eliciting information which provided authentic insight into their experiences (Silverman, 1993). The interview questions were semi-structured and open-ended allowing participants to elaborate on their responses and describefully their individual experiences of growing up in singlemotherhouseholds, without their fathers.

Focus group interview was employed as secondary data collection method for information to supplement individual interview data. Focus group interview is a good qualitative approach for learning about a population group especially regarding conscious, semi-conscious and unconscious psychological and sociological characteristics and processes 
(Basch, 1987). A focus group interview is a discussion designed to obtain perceptions on a defined area of interest in a permissive, non-threatening environment (Krueger, 1988) and has the advantageof obtaining information generated from group interactions of participants involved in exchanges or sharing of information, ideas and experiences (Babbie, \& Mouton, 2005).Two focus group interviews (one group with seven and the other eight participants), ranging between 40 to 60 minutes each, were conducted.

In order not to limit the study to only concentrating on verbal descriptions of participants' experiences, behavioural observation notes and responses to questions on collages compiled were also employed to gather information on the meanings of various factors in their experiential context (Sherman, \& Webb, 1988, Kelly, \& Emery, 2002, Heck, 2006). Observation allowed for conscious focus on participants' interactions and emotional expressions enabling researchers to better understand many aspects of participants' personal experiences (Patton, 2002).

Collage, a formal work of art made from assemblage of different forms,is a user-friendly visual method of data collection especially good for young people (Daniels, 2006). Collages allow for the communication of innermost feelings found difficult to express verbally. Each study participant was asked to compile collages by clipping materials (pictures) from print and other media to indicate their feelings regarding their experiences and their evaluations of various aspects of their single-mother family lives. In creative and non-threatening ways collages provide opportunities for participants to share feelings initially uncomfortable to talk about.

Validity, reliability and trustworthiness of data are a set of criteria with which a study must comply to be regarded as of good quality (Denzin, \& Lincoln, 2005). In this study validity, reliability and trustworthiness were assured by using several methods to explore all dimensions of the phenomenon under investigation and to collect data (Toma, 2006). Data analysis yielded common themes in participants' responses and further assurance of trustworthiness was the return of the interview transcripts and interpretations of data to the participants for verification via a "member check" (Babbie, \& Mouton, 2005).

\subsection{Procedure}

Permission to conduct the study was first obtained from Western Cape Education Department under whose jurisdiction was the community high school involved in this study. Permission to conduct the study was also obtained from the principal of the school by a letter containing information regarding the purpose of study, participants and conditions for participation. Other ethical principles by which the research was framed include informing on the voluntary and anonymous nature of participation, assurance of confidentiality of information and permission for electronic recording of interviews. Since participants were minors written consents to participate in the study were obtained from their parents or legal guardians.All interviews (individual,focus group and interviews on collages) were conducted in private rooms at the school that ensured confidentiality. Observation notes were added to interview transcriptions for data analysis.

\subsection{Data Analysis}

Data analysis was content, thematic and hermeneutic consistent with qualitative data analysis as proposed by Braun and Clarke (2006). The analysis involved multiple readings of the interview transcriptions, summary and organization into emerging patterns and themes corresponding to descriptions of the participants' satisfaction with aspects of their singlemother family life on which they reported. The main categories of themes around which the results are organized include participants'satisfaction with their family status, family financial resources, social support and theirfamily residential environment. The results are "grounded" by uses of excerpts from the interview transcriptions or responses to questions on the collages compiled to accurately describe participants' evaluation of their life satisfaction with the reported domains of their single-mother family lifeas vividly as possible and as if to almost see and hear the participants (Glaser, \& Strauss, 1967).

\section{Results}

Summary results of participants' assessment of life satisfaction with various aspects of their single-mother family life are presented in the Table 1 below. The table displays information on the participants' evaluation of their satisfaction with four aspects of their single-mother family life. Expressions used to evaluate their satisfaction with these aspects of their families are laden with negative affect (including anger, frustration, loneliness, rejection, sadness, unhappiness,fear, insecurity, and indignity) reflecting their poor subjective well-being.

Data analysis results on participants' evaluation of their family status, revealed general dissatisfaction with living in 
single-mother households. The dissatisfaction is expressed variously in forms of general unhappiness and anger because participants felt being deprived of same-sex role models, not exposed to appropriate gender-type reinforcement and not learning appropriate gender roles and behaviours. Participants also reported that single-mother households did not give them safety or security. For instance, many collages compiled featured animals like lions, elephants and cheetahs. When questioned about the significance of these animals, participants responded that they represent power or strength and used them to indicate their feelings of absence of safety and security from their households as consequence of their fathers being absent.

Table 1: Participants'satisfaction with aspects of their single-mother familylife.

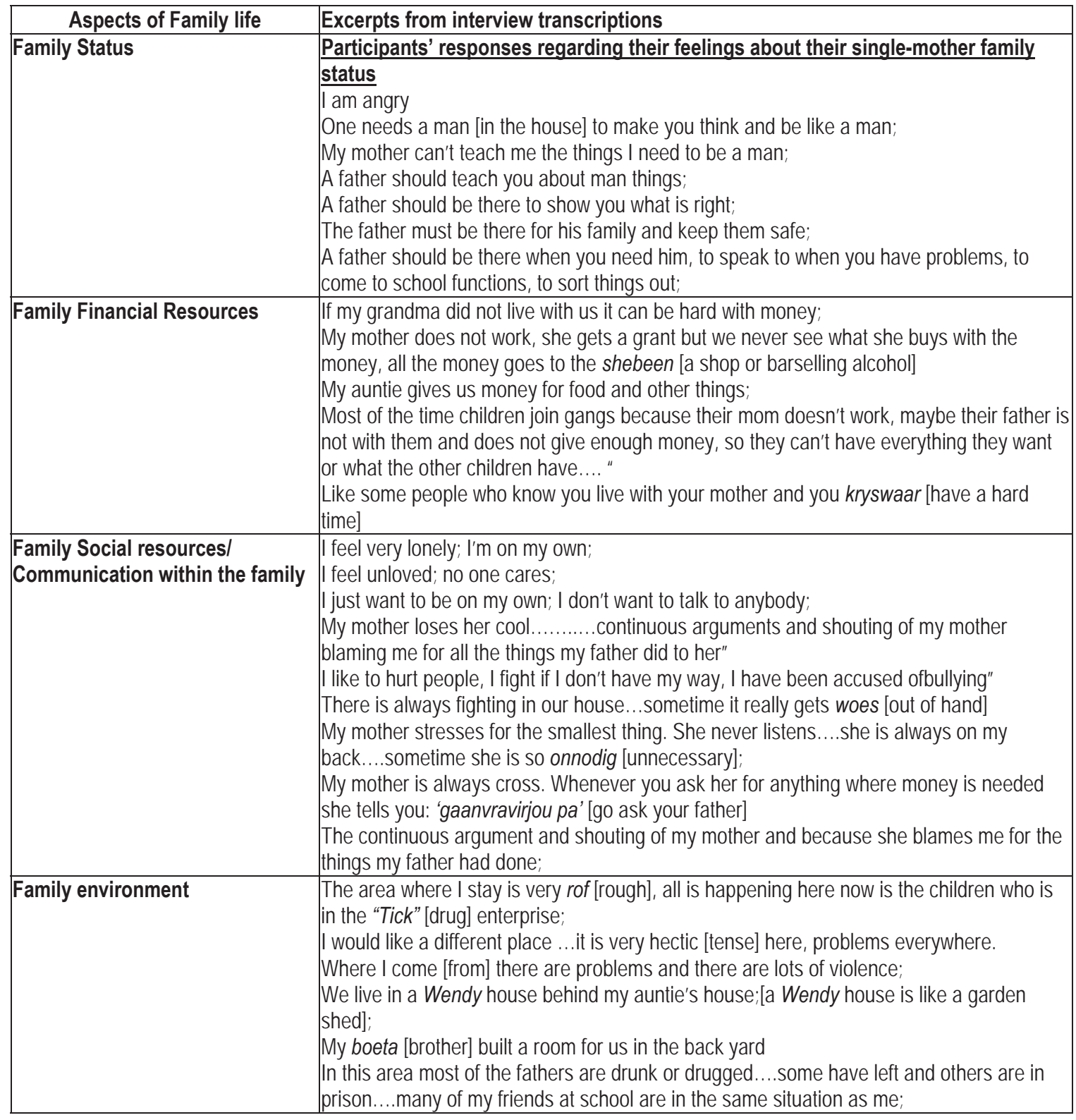

In terms of evaluation of their satisfaction with their family financial resources, most participants reported living with custodial parents who are unemployed and therefore, are exposed to poor socio-economic conditions. Participants felt very unsatisfied with this aspect of their family life and claimed that as consequence led them to at-risk behaviours including joining gangs and abusing drugs.Participants' responses to questions on their family financial conditions indicate that exhibiting at-risk behaviours was perceived as male gender responses to economic hardship (see Table 1). 
Some participants also reported that, to their peers,living in single-mother household means living in a family with financial hardship. Therefore, when in company of their peers who are aware they are from indigent and poor singlemother households, the participants reported that they lack confidence in themselves or develop low self-esteem (see Table 1) to indicate that participants felt unhappy with their family life.

Reactions to financial hardship of their households were also indicated in the collages featuring big houses, expensive cars and aeroplanes (for expensive travel) to indicate not just what the participants aspired to or dreamed of having but also as indication of the economic strength absent from their families.

Reports on social support within their families revealed that participants had little or no interactions with their absent fathers indicating less social support from their fathers. Results also indicate less satisfactory social support even from their mothers,the custodial parents, who themselves were preoccupied with their own problems associated with living without their opposite sex partners. Interactions with mothers are reported to be characterized by conflicts especially when the adolescent boys are unable to perform male-gender specific roles to the satisfaction of the mothers (and as expected of adolescents by one's society). In their search for independence from their parents and their displaying of behaviour tendencies characteristic of their developmental age level, participants reported conflicts with their custodial parents. Attempts to build social relationship with their peers further aggravated such child-parent conflicts especially when such attachment to peer group meant more latitude for exposure tonegative peer models and at-risk behaviour tendencies.Furthermore, participants' reports also revealedthat their custodial parents often project their own frustrations of broken relationship with their partners on their male children especially when the mothers perceived the male children as displaying behaviour tendencies reminding the mothers of the causes ofless fruitful relationship with the fathers of their children.

Family environment was also assessed to be less satisfactory. The poor social economic conditions of their singlemother households meant living in poor or sub-standard housing like what participants described as "Wendy" house - a garden shed or backyard house. The outside environment of their households was also unsatisfactory because of violence which evoked strong negative feelings around safety and security by the participants.

\section{Discussion}

The study explored the subjective well-being of some adolescent boys living in single-mother households in a suburb of Cape Town, South Africa, as revealed in their reported experiences on their assessment of satisfaction with certain aspects of their single-mother family life including satisfaction with their family status, financial resources, social interactions and support and family living environment.

The links between many different family variables and children's happiness, health, optimal adjustment to life and or subjective well-being as revealed by this study are consistent with findings by previous studies especially those outside of Africa. For instance, Laftman (2010) found that when it comes to the description of one's household as not satisfactory or "not well off" children in single-mother households tend to report this more often than their peers living with two original parents. One fundamental difference between two-parent and single-mother families has been found to be related to the economy of the households (Laftman, 2010). According to McLanahan (2008), the single most important factor contributing to difficulties or unsatisfactory experiences by children in single-mother households is the low family income. McLanahan further asserts that households headed by single mothers have significantly fewer financial resources and reduced access to all the advantages money can buy. No child can be satisfied living in household which does not provide adequate financial support for proper nourishment, protection, safety, security and even for parental social and emotional support as well as encouragement to go to school and remain in school, plan for appropriate career future and adjust fairly adequately well to life (Zimmerman, \& Thayer, 2003). Bojuwoye and Akpan (2009) also assert that households with poor financial resource are likely to have children who are less motivated and have lower aspirations for their education, career future and for life in general. Poor financial resource is responsible for single-mother households being located in small residences, backyard dwellings,substandard housing and in the areas of town with increased violence, lower quality schools and loss of familiar and developed community support, all of which negatively impact children's physical, psychological and social well-being (McLanahan, 2008). The general contention by Laftman (2010) is that unsatisfactory financial status of family is likely to contribute to poor subjective well-being or overall dissatisfaction with life.

The study participants reported dissatisfaction with social support within single-mother households. Laftman (2010) found children in single-mother households to have lower social support from parents and fewer material resources hence their poorer health conditions in comparison with children living with two original parents. One explanation for the participants' reported dissatisfaction with the social support within their single-mother households may be because of the 
stage of physical development of the participants who being adolescents were in search of their identity (male identity for that matter) which cause them to experience conflicts with their opposite-sex parents (their mothers) (Bojuwoye, \& Sylvester, 2012). McHale et al (2000) note that as adolescents go through the process of identity formation and trying to assert their independence from their parents they may encounter strains in their relationships with the parents. Bojuwoye et al. (2012) also report that adolescent boys in single-mother households often find communication with their oppositesex parents very difficult. Generally conflict with parents is a key process of adolescence, as both parents and adolescents simultaneously negotiate changes in the relationships resulting from transition through adolescence (Updegraff, Delgado and Wheeler, 2008). However, constant conflicts with parents have negative psychological impact on children's adjustment and well-being (Bojuwoye et al. 2009), whereas good interpersonal relationships with parents make for positive adjustment and health (McLanahan, 2008).

The parental differential treatment and in particular the tendency to treat boys who display more aggression with less favour than girls could also account for participants' experiences of poor social support within their single-mother households. However a more important explanation with the participants' dissatisfaction with social support in their singlemother households may be because of the absence of their fathers. Amato (1994) found that contact with fathers by children in single-mother house-holds does impact on the children's well-being. Absence of father from household may be perceived by children as a block in the connectedness or connectivity between the feelings, beliefs, actions and behaviours of various types of social actors in the family (Mooij, 2012). A family life devoid of contact with one of the parents strongly associated with family's financial strength, safety and security,certainly,cannot but receive negative assessment.

\section{Conclusion}

The assessment of life satisfaction or subjective well-being of the participants of this cannot be said to be satisfactory or optimal as these are laden with negative affect and at-risk behaviour tendencies. Important elements for their optimal or satisfactory subjective well-being which include emotional integrity or sense of self-worth, social support and economic well-being are lacking in households they lived as the reports showed that the participants perceived that they were not provided with care, support, safety or protection, and training in positive values and health promoting behaviours. As has been found by studies in other cultures of the world, both provision and protection orsafety and security as well as health complaints and less than satisfactory adjustment to life and well-being have been found to be more common among children in single-mother households than among children living with two original parents. The implication of this finding is that the households in which children live without the complement of the two parents (same-sex parents, mothers and fathers) may be said to be "dysfunctional" somewhat. However, the popularity of single-parent households means that they are likely to continue to grow in number and many more children would have to contend with living in such households. This then leads to another implication that what children need for their emotional, social and behavioural well-being and overall adjustment to life have to be sourced outside of their "dysfunctional" homes which have become increasingly incapable of providing these. The more likely and acceptable places to find these are the schools. This, therefore, means that schools have to take up additional responsibilities in children's development. Teachers alone cannot take up these responsibilities. Professional helpers (psychologists, counsellors, social workers) and other social services personnel would have to be provided to implement effective preventive and intervention strategies as well as support services for dealing with the negative consequences associated with single-parent households and for ensuring the overall well-being of affected children.

The findings of this study also have very important political implications. Financial insecurity of single-parent households is a major contributor to affected children's negative cognitive,emotional and health outcomes. Family economic welfare goes a long way in ensuring children's satisfactory subjective well-being. This, therefore, implies that government policies on children and families would need to be relooked or strengthened and to ensure that families are supported in order to improve children's health, overall adjustment to life or satisfactory subjective well-being. Some form of public or government financed parental healthcare and support systems may need to be put in place if favourable subjective well-being or overall adjustment to life of children is to be ensured.

\section{References}

Acklin, M. W. (2008). Divorce your spouse not the kids. [Online] Available: http/:www.divorcesource.com/HI/ARTICLES/acklin2.htm1 (September 24,2009.)

Amato, P. R.(1994). Lifespan adjustment of children to their parents' divorce. Future Child, 4,143-146. 
Babbie,E, \& Mouton, J. (2005). The practice of social research. Cape Town: Oxford University Press.

Basch, C. E. (1987). Focus group interview: An under-utilized research technique for improving theory and practice in health education. Health Education Quarterly, 14, 411-448.

Bless, C.,\& Smith, H. (1996). Fundamentals of social research. Cape Town: Juta \& Co.

Bodgan, R, \& Taylor, S. J. (1999). Introduction to quantitative research methods: A guidebook and resource. Chichester:John Wiley.

Bojuwoye, O., \& Akpan, O. (2009). Children's reactions to divorce of parents. The OpenFamily Studies Journal, 2, 75-81.

Bojuwoye O., \& Sylvester, F. (2012). Patterns of gender socialization of adolescent boys insingle-mother households: Perspectives from a community in Cape Town, South Africa. Gender, Technology and Development, 16, 197-222.

Braun, V.,\& Clarke, V. (2006).Using thematic analysis in psychology.Qualitative Research in Psychology, 3, 77 - 101.

Bronfenbrenner, U. (1979). Two worlds of childhood: U.S. and U.S.S.R.New York: Russel Sage Foundation

Carr W., \& Kemmis, S. (1986). Becoming critical: education, knowledge and action research. London: Falmer.

Chapple, S. (2009).Child well-being and sole-parent family structure in the OECD: An analysis.OEDC Social Employment and Migration Working Papers.Directorate for Employment, Labor and Social Affairs, Paris: OECD.

Chen, N. (2007). The impact of father absence. Focus on kids. [Online] Available: http://extension.missouri.edu/cooper/fok/father_ absence.htm (June 15, 2008).

Crouch, M, \& McKenzie H. (2006). The logic of small samples in interview-based qualitative research. Social Science Information, 45 , 483.

Daniels, D. (2006). Using visual methods to bring marginalized people to the centre. In S.B. Merriam, B. C. Courtenay, \& R.M Cervero (Eds.), Global issues and adult education: Perspectives from Latin America, South Africa and the United States. San (pp. 199201). San Francisco: Jossey-Bass..

Daniles, D., \& Adams, Q. (2009). Breaking with township gangsterism: the struggle for place and voice. Paper presented at the Qualitative Inquiry congress, Urbana-Champaign, USA, 20 - 23 May 2009.

Denny, M. K., \& Martin, B. R. (2004. The effects of father absence on adolescent self-concept. Adolescent development: current issues. [Online] Available: http://education.ucsb.edu/jimerson/adolescenceissues/ADdadabsent.html. (November 23, 2008).

Denzin, N. K., \& Lincoln, Y. S. (2005). The SAGE handbook of qualitative research (3rd ed.), Thousand Oaks, CA: Sage

Diener, Ed. (2009). The science of well-being: The collected works of Ed Diener (Ed.), Social Indicators Research SeriesVol. 37, Spinger

Diener, E., Suh, E. M., Lucas, R. E., \& Smith, H. L.(1999). Subjective well-being: Three decades of progress. Psychological Bulletin, 125, 276-302.

Fraley, R.C. (2010). A brief overview of adult attachment theory and research. [Online] Available::http://internal.psychology. illinois.edu/ rcfraley/attachment.htm (August 26, 2011)

Glaser, B.G, \& Strauss, A. L. (1967). The discovery of grounded theory: Strategies for qualitative research.Chicago: Aldine.

Griesel-Roux, E., Ebersöhn, L., Smit, B., \& Elloff, I.(2005). HIVIAIDS programmes: what do learners want? South African Journal of Education, 25, 253-257.

Hazan, C, \& Shaver, P. R. (1994). Attachment as an organizational framework for research on close relationships. Psychological Inquiry, $5,1-22$

Heck, R. H. (2006). Conceptualizing and conducting meaningful research studies in education. In C. F. Conrad, \& R. C. Serlin (Eds.), The Sage handbook for research in education: Engaging ideas and enriching inquiry (pp.373-392). London: Sage.

Hitchcock, G., \& Hughes, D. (1999). Research and the teacher: A qualitative introduction to school-based research. New York: Routledge.

Kelly, J. B., \& Emery, R. E. (2002). Children's adjustment following divorce: Risk and resiliency perspectives. Family Relations, 52, 352362

Krueger, R. A. (1988). Focus groups: A practical guide for applied research. Newbury Park, CA: Sage Publications.

Laftman, S. B. (2010). Family structure and children's living conditions.A comparative study of 24 countries. Child Indicators Research, 3 , 127-147

Lahikainen, A.R., Tolomen, K., \& Kraav, I. (2008).Young children's subjective well-being and family discontents in a changing cultural context. Child Indicators Research,1, 65 - 85

MacCallum, F., \& Golombok, S. (2004). Children raised in fatherless families from infancy: A follow-up of children of lesbian and single heterosexual mothers at early adolescence. Journal of Child Psychology \& Psychiatry, 45, 1407-1419.

Mash, E.J., \& Wolfe, D.A. (2002). Abnormal child psychology. ( $3^{\text {rd }}$ ed.). Belmont: Thomas Wadsworth.

McHale, S. M., Updegraff, K.A., Jackson-Newsom, J., \& Crouter, A. C. (2000). When does parents' differential treatment have negative implications for siblings? Social Development, 9, 149-172.

McLanahan S. (2008). Father absence and the welfare of children. [Online] Available: http://www.olin.wustl.edu/macarthur/working\%20 papers/wp-mclanahan2.htm (February 27, 2008)

Merriam, S. B. (2002). Qualitative research in practice: Examples for discussion and analysis. San Francisco: Jossey-Bass.

Mooij., T. (2012). Personal, family and school influences on secondary pupils' feelings of safety at school in the school surroundings and at home. Teachers and Teaching: Theory and Practice. 18, 129 - 157.

Naran J. (2006). The faltering lure of marriage. Tribune Herald, South Africa, August 20, p.4

Patton, M. Q. (2002). Qualitative research and evaluation methods.(3rd ed).

Thousand Oaks: Sage Publications.

Pike, L. T. (2000). Single mum or single dad?Effects of parent residency arrangements on the development of primary school-aged 
children. Family Matters, 5, $40-45$

Pleck, J. H. (1997). Parental involvement: Levels, sources and consequences. In Lamb ME. (ed). The role of the father in child development (3rd ed.), (pp. 66-103). New York: Wiley.

Popenoe, D. (1996). Life without a father.Cambridge: HarvardUniversity Press.

Prince, C. (2009). The changing face of South African family: Single moms now the norm. Sunday Times, South Africa, July 12, p. 3.

Roberts, J. A., \& Clement, A. (2007). Materialism and satisfaction with overall quality of life and eight life domains. Social Indicators Research, 82, 79 - 92

Sharma, D., \& Silbereisen, R. (2007). Revisiting an era in Germany from the perspective of adolescents in mother-headed single-parent families. International Journal of Psychology, 42, 46-58.

Sherman, R., \& Webb, R. (1988). Qualitative research in education: Focus and methods. London: Falmer.

Silverman, D. (1993) Interpreting qualitative data: Methods for analyzing talk, text and interaction. London: Sage.

Sylvester, T. (2010). At risk youth: The experiences of adolescent boys with absent fathers. Master's degree dissertation. Stellenbosch University, South Africa.

Tanner, J. L. (2002). Parental separation and divorce: Can we provide an ounce of prevention Pediatrics, 110(5). 1007 - 1009.

Terre-Blanche, M., \& Durrheim, K. (1999). Research in practice: Applied methods for the social sciences. Cape Town: University of Cape Town Press.

Toma, J.D. (2006). Approaching rigor in applied qualitative research. In Conrad, C.F,

C. F,.Serlin, R.C. (eds.), The Sage handbook for research in education: Engaging ideas and enriching inquiry (pp. 405-424). London: Sage.

Updegraff, K.A., Delgado, M.Y., \& Wheeler, L.A. (2008). Exploring mothers' and fathers' relationships with sons versus daughters: Links to adolescent adjustment in Mexican immigrant families. Sex Roles: A Journal of Research, 60, 559-574.

Vaaden-Kiernan, N., Ialongo, N.S, Pearson, J, \& Kellam, S. (1995). Household family structure and children's aggressive behavior: a longitudinal study of urban elementary school children. Journal of Abnormal Child Psychology, 23, 553-568.

Wiechers, B. (2003). The emotional and academic outcomes of a group intervention programme on adolescence divorce. What learning means. London: Institute of Education, University of London.

Wright, R. (1994). Rite of Passage. New York: Harper Collins.

Zimmerman, J. \& Thayer, E.S. (2003). Adult children of divorce: how to overcome the legacy of your parents' breakup and enjoy love, trust and intimacy. Oakland, California: New Harbiner Publications Inc. 